\title{
Combined Economic Emission Dispatch Solution using Simulated Annealing Algorithm
}

\author{
Hardiansyah $^{1}$, Junaidi $^{2}$, Yandri $^{3}$ \\ ${ }^{1,2,3}$ (Department of Electrical Engineering, University of Tanjungpura, Indonesia)
}

\begin{abstract}
This paper present a simulated annealing (SA) algorithm for solving the combined economic emission dispatch (CEED) problem in power systems considering the power limits. The CEED is to minimize both the operating fuel cost and emission level simultaneously while satisfying the load demand and operational constraints. The philosophy involves the introduction of a new decision variable through a prudent mathematical transformation of the relation between the decision variable and the optimal generations. A novel best mechanism algorithm based on global optimization approaches is inspired by annealing process of thermodynamics. Numerical results for the standard IEEE 30-bus 6-generator test system have been presented to illustrate the performance and applicability of the proposed approach. The results obtained are compared to those reported in the recent literature. Those results show that the proposed algorithm provides effective and robust high-quality solution of the CEED problem.
\end{abstract}

Keywords: Economic dispatch, emission dispatch, combined economic emission dispatch, simulated annealing algorithm, global optimization.

\section{Introduction}

The principal objective of the economic dispatch (ED) problem is to find a set of active power delivered by the committed generators to satisfy the required demand subject to the unit technical limits at the lowest production cost. Therefore, it is very important to solve the problem as quickly and precisely as possible $[1,2]$. Therefore, recently most of the researchers made studies for finding the most suitable power values produced by the generators depending on fuel costs. In these studies, they produced successful results by using various optimization algorithms [3-5]. Despite the fact that the traditional ED can optimize generator fuel costs, it still cannot produce a solution for environmental pollution due to the excessive emission of fossil fuels.

Currently, a large part of energy production is done with thermal sources. Thermal power plant is one of the most important sources of carbon dioxide $\left(\mathrm{CO}_{2}\right)$, sulfur dioxide $\left(\mathrm{SO}_{2}\right)$ and nitrogen oxides $\left(\mathrm{NO}_{\mathrm{x}}\right)$ which create atmospheric pollution [6]. Emission control has received increasing attention owing to increased concern over environmental pollution caused by fossil based generating units and the enforcement of environmental regulations in recent years. Numerous studies have emphasized the importance of controlling pollution in electrical power systems [7].

Combined economic and emission dispatch (CEED) has been proposed in the field of power generation dispatch, which simultaneously minimizes both fuel cost and pollutant emissions. When the emission is minimized the fuel cost may be unacceptably high or when the fuel cost is minimized the emission may be high. A number of methods have been presented to solve CEED problems such as genetic algorithm [8], artificial bee colony algorithm $[9,10]$, analytical solution [11, 12], particle swarm optimization [13, 14], and biogeography based optimization [15].

This paper proposes a SA algorithm to solve the CEED problem. The performance of the proposed algorithm is tested on the standard IEEE 30-bus 6-generator test system. Numerical results obtained by the proposed approach were compared with other optimization results reported in the recent literature.

\section{Problem Formulations}

The economic emission dispatch (EED) problem targets to find the optimal combination of load dispatch of generating units and minimizes both fuel cost and emission while satisfying the total power demand. Therefore, EED consists of two objective functions, which are economic and emission dispatches. Then these two functions are combined to solve the problem. The EED problem can be formulated as follows [8]:

$$
F_{T}=\operatorname{Min} f(F C, E C)
$$

where $F_{T}$ is the total generation cost of the system, $F C$ is the total fuel cost of generators and $E C$ is the total emission of generators. 


\subsection{Economic Dispatch (ED)}

The ED problem targets to find the optimal combination of power generation by minimizing the total fuel cost of all generator units while satisfying the total demand. The ED problem can be formulated in a quadratic form as follows:

$$
F_{C}=\sum_{i=1}^{N}\left(a_{i} P_{i}^{2}+b_{i} P_{i}+c_{i}\right)
$$

where $P_{i}$ is the power generation of the $i$ th unit; $a_{i}, b_{i}$, and $c_{i}$ are fuel cost coefficients of the $i$ th generating unit and $N$ is the number of generating units.

\subsection{Emission Dispatch (ED)}

The classical ED problem can be obtained by the amount of active power to be generated by the generating units at minimum fuel cost, but it is not considered as the amount of emissions released from the burning of fossil fuels. Total amount of emissions such as $\mathrm{SO} 2$ or NOx depends on the amount of power generated by until and it can be defined as the sum of a quadratic function as follows:

$$
E C=\sum_{i=1}^{N}\left(\alpha_{i} P_{i}^{2}+\beta_{i} P_{i}+\gamma_{i}\right)
$$

where $\alpha_{i}, \beta_{i}$ and $\gamma_{i}$ are emission coefficients of the $i$ th generating unit.

\subsection{Combined Economic Emission Dispatch (CEED)}

CEED is a multi-objective problem, which is a combination of both economic and environmental dispatches that individually make up different single problems. At this point, this multi-objective problem needs to be converted into single-objective form in order to fulfill optimization. The conversion process can be done by using the price penalty factor. However, the single-objective EED can be formulated as shown in equation (4) $[8,10]$ :

$$
\operatorname{Min} F_{T}=\sum_{i=1}^{N}\left(\left(a_{i} P_{i}^{2}+b_{i} P_{i}+c_{i}\right)+h_{i}\left(\alpha_{i} P_{i}^{2}+\beta_{i} P_{i}+\gamma_{i}\right)\right)(\$ / h)
$$

where $h_{i}$ is the price penalty factor, and is formulated as follows:

$$
h_{i}=\frac{a_{i} P_{i \max }^{2}+b_{i} P_{i \max }+c_{i}}{\alpha_{i} P_{i \max }^{2}+\beta_{i} P_{i \max }+\gamma_{i}}
$$

where $P_{i \max }$ is the maximum power generation of the $i$ th unit in MW.

\subsection{Problem Constraints}

There are two constraints in the EED problem which are power balance constraint and maximum and minimum limits of power generation output constraint.

Power balance constraint:

$$
\begin{aligned}
& \sum_{i=1}^{N} P_{i}=P_{D}+P_{L} \\
& P_{L}=\sum_{i}^{N} \sum_{j}^{N} B_{i j} P_{i} P_{j}
\end{aligned}
$$

Generating capacity constraint:

$$
P_{i \text { min }} \leq P_{i} \leq P_{i \text { max }}
$$

where:

$$
\begin{aligned}
& P_{D}=\text { Total demand of the system }(\mathrm{MW}) \\
& P_{L}=\text { Total power loss }(\mathrm{MW}) \\
& P_{i \min }=\text { Minimum generation of unit } i(\mathrm{MW}) \\
& P_{i \text { max }}=\text { Maximum generation of unit } i(\mathrm{MW}) \\
& B_{i j}=\text { Coefficients of transmission losses. }
\end{aligned}
$$

The conditions for optimality can be obtained by using Lagrangian multipliers method and Kuhn Tucker conditions as follows [1]:

$$
\operatorname{Min} L=F_{T}-\left(\sum_{i}^{N} P_{i}-P_{D}-P_{\text {Loss }}\right), i=1,2, \ldots, N
$$

Equation coordination of these functions can be obtained as 


$$
\frac{d L\left(P_{i}\right)}{d P_{i}}=2\left(a_{i}+h_{i} \alpha_{i}\right) P_{i}+\left(b_{i}+h_{i} \beta_{i}\right)=\lambda
$$

The above equation can be solved iteratively to EED impose on the boundary of the generation and power balance equation as a constraint.

\subsection{Overview}

\section{Simulated Annealing Algorithm}

Simulated annealing is an optimization technique that simulates the physical annealing process in the field of combinatorial optimization. Annealing is the physical process of heating up a solid until it melts, followed by slow cooling it down by decreasing the temperature of the environment in steps. At each step, the temperature is maintained constant for a period of time sufficient for the solid to reach thermal equilibrium. At any temperature $T$, the thermal equilibrium state is characterized by the Boltzmann distribution. This distribution gives the probability of the solid being in a state $i$ with energy $E_{i}$ at temperature $T$ as

$$
P_{i}(T)=k \exp \left(-E_{i} / T\right)
$$

where $k$ is a constant.

Metropolis et al. [16] proposed a Monte Carlo method to simulate the process of reaching thermal equilibrium at a fixed value of the temperature $T$. In this method, a randomly generated perturbation of the current configuration of the solid is applied so that a trial configuration is obtained. Let $E_{\mathrm{c}}$ and $E_{t}$ denote the energy level of the current and trial configurations, respectively. If $E_{t}<E_{c}$; then a lower energy level has been reached, and the trial configuration is accepted and becomes the current configuration. On the other hand, if $E_{t} \geq E_{c}$ the trial configuration is accepted as current configuration with probability proportional to exp $(\Delta E / T)$, $\Delta E=E_{t}-E_{c}$. The process continues until the thermal equilibrium is achieved after a large number of perturbations, where the probability of a configuration approaches Boltzmann distribution $[17,18]$.

By gradually decreasing the temperature $T$ and repeating Metropolis simulation, new lower energy levels become achievable. As $T$ approaches zero least energy configurations will have a positive probability of occurring. The general algorithm of SA can be described in steps as follows:

Step 1: Set the initial value of $C_{\mathrm{p} 0}$ and randomly generate an initial solution $x_{\text {initial }}$ and calculate its objective function. Set this solution as the current solution as well as the best solution, i.e. $x_{\text {initial }}=x_{\text {current }}=x_{\text {best }}$

Step 2: Randomly generate an $n_{1}$ of trial solutions in the neighborhood of the current solution.

Step 3: Check the acceptance criterion of these trial solutions and calculate the acceptance ratio. If acceptance ratio is close to 1 go to Step 4; else set $C_{\mathrm{p} 0}=\alpha \cdot C_{\mathrm{p} 0} ; \alpha>1$; and go back to Step 2 .

Step 4: $\quad$ Set the chain counter $k=0$.

Step 5: Generate a trial solution $x_{\text {trial. }}$. If $x_{\text {trial }}$ satisfies the acceptance criterion set $x_{\text {current }}=x_{\text {trial }}, J\left(x_{\text {current }}\right)=$ $J\left(x_{\text {trial }}\right)$ and go to Step 6; else go to Step 6.

Step 6: Check the equilibrium condition. If it is satisfied go to Step 7; else go to Step 5.

Step 7: Check the stopping criteria. If one of them is satisfied then stop; else set $k=k+1$ and $C_{\mathrm{p}}=\mu \cdot C_{\mathrm{p}} ; \mu<$ 1 ; and go back to Step 5 .

\section{2. $\quad$ Proposed SA}

In all the existing SA algorithm based approaches for solving ELD problems, the real power generation of all generating units are considered as the decision variables that makes the size of the problem vary large, slow down the speed of these algorithms and hence not suitable for systems having larger number of generating units. In the proposed approach, the penalty factor $\lambda$ of the classical $\lambda$ - iteration is considered as the only decision variable irrespective of the number of generating units. The real power of all the generating plants are considered as the problem dependant variables and expressed as a function of $\lambda$. The real power generations are computed using (10) for each $\lambda$ value obtained during the SA iterations.

The lower and upper limits of the decision variable- $\lambda$ depend on the minimum and maximum power demands that the system can supply. The first step in obtaining these values is to compute the lower and upper incremental cost values by substituting the respective to real power limits in (10) for all the plants as

$$
\begin{aligned}
& I C_{i}^{\min }=2\left(a_{i}+h_{i} \alpha_{i}\right) P_{i}^{\min }+\left(b_{i}+h_{i} \beta_{i}\right) \\
& I C_{i}^{\max }=2\left(a_{i}+h_{i} \alpha_{i}\right) P_{i}^{\max }+\left(b_{i}+h_{i} \beta_{i}\right)
\end{aligned}
$$

The next step is choosing the lowest and highest incremental cost value, obtained from (12), as the limits for $\lambda$.

$$
\begin{aligned}
& \lambda^{\min }=\min \left(I C_{1}^{\min }, I C_{2}^{\min }, \ldots, I C_{N}^{\min }\right) \\
& \lambda^{\max }=\max \left(I C_{1}^{\max }, I C_{2}^{\max }, \ldots, I C_{N}^{\max }\right)
\end{aligned}
$$

The SA searches for the optimal solution by minimizing a cost function. In the proposed formulation, the net fuel cost of all the generating plant is considered as the cost function. However, a penalty term is 
included in the cost function to handle the explicit power balance constraint. The penalty term increases the cost function for infeasible solutions. The cost function is therefore built as a blend of fuel cost function and the power balance constraint through the use of a penalty factor as

Minimize $F_{T}=\sum_{i=1}^{N} F_{i}\left(P_{i}\right)+\lambda\left[\sum_{i=1}^{N} P_{i}-P_{D}-P_{\text {Loss }}\right]$

The number of decision variables in this formulation is always one, whereas the existing SA based approaches require the generation of all the plants as the variables. This reduction in decision variables will reduce the overall computational burden and improves the convergence rate. The algorithm of the proposed SA for solving the CEED problem is outlined.

1. Read the input data of the CEED problem

2. Set $k=0$

3. Choose initial temperature $T_{t}$, cooling coefficient $\alpha$, number of iterations for each temperature $N_{t}$ and maximum number of iterations $N_{\max }$.

4. Choose a random start point $\lambda_{0}$ within the specified range

5. Repeat the following:

a. Select a random point $\lambda_{\mathrm{k}}$ from the neighbourhood of $\lambda_{0}$ within the specified range

b. Solve (10) for $P_{i}$ while imposing the limits given by (8)

c. Calculate $F_{T}^{k}$ using (14)

d. If $F_{T}^{k}<F_{T}^{0}$ then accept the trial solution by setting $\lambda_{0}=\lambda_{k}$

Else select a random number $\mathfrak{R}$ in the range $[0,1]$

If $P(T)>\mathfrak{R}$, then $\lambda_{0}=\lambda_{k}$, otherwise discard the trial point

e. Check convergence by comparing the number of iterations $k$ with $N_{\max }$

If converged, stop and print the CEED corresponding to the $\lambda_{0}$. Otherwise, set $k=k+1$

6. Reduce the temperature by the factor $\alpha$ and go to step 5 .

\section{Simulation Results And Discussion}

In the study of experiment, SA algorithm is tested over standard IEEE 30-bus 6-generator test system as shown in Figure 1. The parameters of all thermal units are presented in Table I, followed by $B$-loss coefficient $[8,10,12]$.

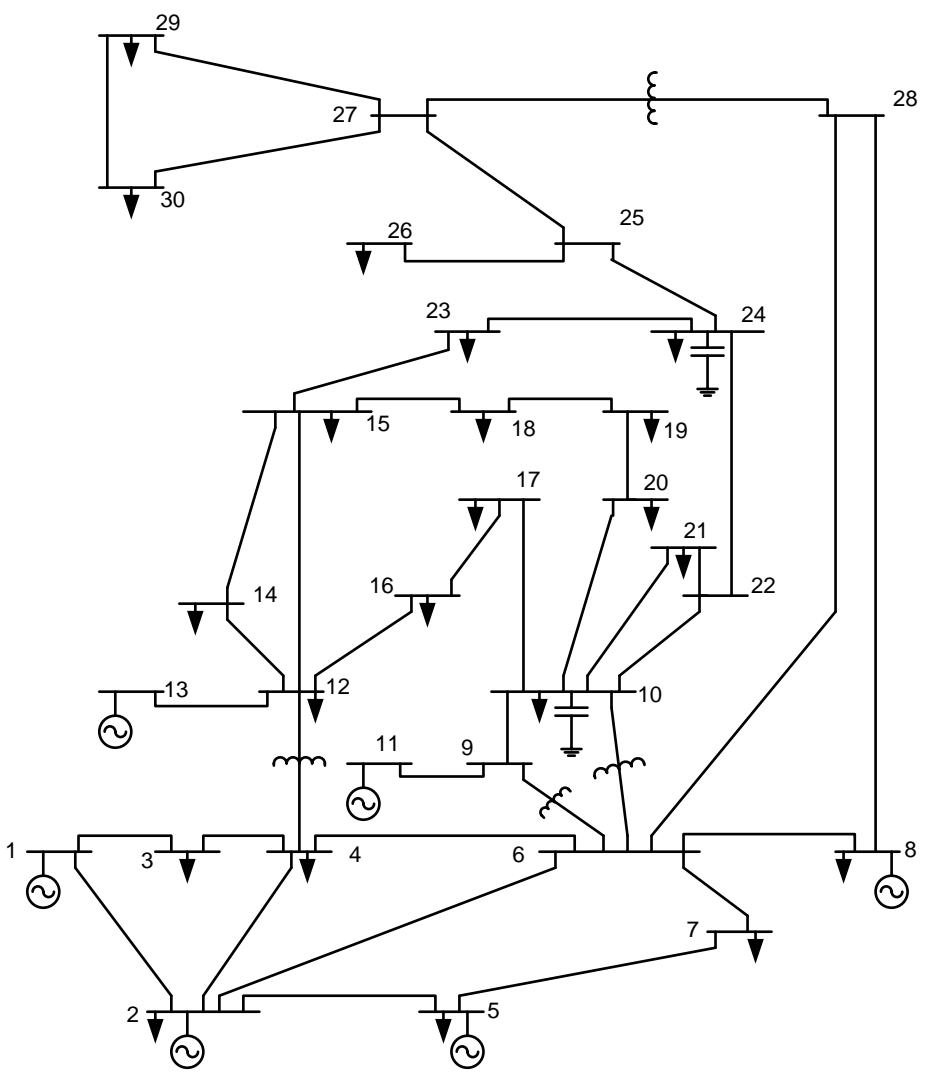

Figure 1 Single-line diagram of IEEE 30-bus test system [10] 
The proposed technique is applied for CEED problem with load demands $500 \mathrm{MW}, 700 \mathrm{MW}$, and 900 MW, respectively and it is compared with FCGA and NSGA-II [19]. Minimum fuel cost solution for CEED problem with all load demands are considered respectively in Table II, Table III, and Table IV. Minimum $\mathrm{NO}_{\mathrm{x}}$ emission effect solution for CEED problem with all load demands are considered respectively in Table V, Table VI, and Table VII. The best compromise solution for CEED problem with all load demands are considered respectively in Table VIII, Table IX, and Table X.

Table I Generator capacity limits, fuel cost and emission coefficients for IEEE 30-bus test system

\begin{tabular}{|c|l|l|c|c|c|c|c|c|}
\hline Unit & $\begin{array}{l}P_{i}^{\text {min }} \\
(\mathrm{MW})\end{array}$ & $\begin{array}{l}P_{i}^{\max } \\
(\mathrm{MW})\end{array}$ & $\begin{array}{c}\mathrm{a}_{\mathrm{i}} \\
\left(\$ / \mathrm{MW}^{2}\right)\end{array}$ & $\begin{array}{c}\mathrm{b}_{\mathrm{i}} \\
(\$ / \mathrm{MW})\end{array}$ & $\begin{array}{c}\mathrm{c}_{\mathrm{i}} \\
(\$)\end{array}$ & $\begin{array}{c}\alpha_{\mathrm{i}} \\
\left(\$ / \mathrm{MW}^{2}\right)\end{array}$ & $\begin{array}{c}\beta_{\mathrm{i}} \\
(\$ / \mathrm{MW})\end{array}$ & $\begin{array}{c}\gamma_{\mathrm{i}} \\
(\$)\end{array}$ \\
\hline 1 & 10 & 125 & 0.15240 & 38.53973 & 756.79886 & 0.00419 & 0.32767 & 13.85932 \\
\hline 2 & 10 & 150 & 0.10587 & 46.15916 & 451.32513 & 0.00419 & 0.32767 & 13.85932 \\
\hline 3 & 35 & 225 & 0.02803 & 40.39655 & 1049.9977 & 0.00683 & -0.54551 & 40.26690 \\
\hline 4 & 35 & 210 & 0.03546 & 38.30553 & 1243.5311 & 0.00683 & -0.54551 & 40.26690 \\
\hline 5 & 130 & 325 & 0.02111 & 36.32782 & 1658.5596 & 0.00461 & -0.51116 & 42.89553 \\
\hline 6 & 125 & 315 & 0.01799 & 38.27041 & 1356.6592 & 0.00461 & -0.51116 & 42.89553 \\
\hline
\end{tabular}

$$
B_{i j}=\left[\begin{array}{rrrrrr}
0.002022 & -0.000286 & -0.000534 & -0.000565 & -0.000454 & -0.000103 \\
-0.000286 & 0.003243 & 0.000016 & -0.000307 & -0.000422 & -0.000147 \\
-0.000534 & 0.000016 & 0.002085 & 0.000831 & 0.000023 & -0.000270 \\
-0.000565 & -0.000307 & 0.000831 & 0.001129 & 0.000113 & -0.000295 \\
-0.000454 & -0.000422 & 0.000023 & 0.000113 & 0.000460 & -0.000153 \\
-0.000103 & -0.000147 & -0.000270 & -0.000295 & -0.000153 & 0.000898
\end{array}\right]
$$

Table II Best fuel cost for 6-generator system $\left(\mathrm{P}_{\mathrm{D}}=500 \mathrm{MW}\right)$

\begin{tabular}{|l|c|c|c|}
\hline Unit Output & FCGA & NSGA-II & SA \\
\hline P1 (MW) & 49.47 & 50.836 & 52.1024 \\
\hline P2 (MW) & 29.40 & 31.806 & 29.0471 \\
\hline P3 (MW) & 35.31 & 35.12 & 40.0000 \\
\hline P4 (MW) & 70.42 & 73.44 & 68.0901 \\
\hline P5 (MW) & 199.03 & 191.988 & 191.4150 \\
\hline P6 (MW) & 135.22 & 135.019 & 136.4637 \\
\hline Fuel cost (\$/h) & 28150.80 & 28150.834 & 28086.9456 \\
\hline Emission (kg/h) & 314.53 & 309.04 & 306.3324 \\
\hline Power losses (MW) & 18.86 & 18.208 & 17.1183 \\
\hline Total Capacity (MW) & 518.86 & 518.208 & 517.1183 \\
\hline
\end{tabular}

Table III Best fuel cost for 6-generator system $\left(\mathrm{P}_{\mathrm{D}}=700 \mathrm{MW}\right)$

\begin{tabular}{|l|c|c|c|}
\hline Unit Output & FCGA & NSGA-II & SA \\
\hline P1 (MW) & 72.14 & 76.179 & 76.0897 \\
\hline P2 (MW) & 50.02 & 51.81 & 49.0586 \\
\hline P3 (MW) & 46.47 & 49.82 & 45.3525 \\
\hline P4 (MW) & 99.33 & 103.407 & 102.7347 \\
\hline P5 (MW) & 264.60 & 267.984 & 266.3914 \\
\hline P6 (MW) & 203.58 & 184.734 & 191.3422 \\
\hline Fuel cost (\$/h) & 38384.09 & 38370.746 & 38207.5910 \\
\hline Emission (kg/h) & 543.48 & 534.924 & 532.6970 \\
\hline Power losses (MW) & 36.15 & 33.934 & 30.9692 \\
\hline Total Capacity (MW) & 736.14 & 733.934 & 730.9692 \\
\hline
\end{tabular}

Table IV Best fuel cost for 6-generator system $\left(\mathrm{P}_{\mathrm{D}}=900 \mathrm{MW}\right)$

\begin{tabular}{|l|c|c|c|}
\hline Unit Output & FCGA & NSGA-II & SA \\
\hline P1 (MW) & 101.11 & 102.963 & 103.4811 \\
\hline P2 (MW) & 67.64 & 74.235 & 70.1005 \\
\hline P3 (MW) & 50.39 & 66.003 & 60.6818 \\
\hline P4 (MW) & 158.80 & 140.316 & 139.5618 \\
\hline P5 (MW) & 324.08 & 324.888 & 325.0000 \\
\hline P6 (MW) & 256.56 & 248.416 & 251.7912 \\
\hline Fuel cost (\$/h) & 49655.40 & 49620.824 & 49297.9331 \\
\hline Emission (kg/h) & 877.61 & 849.326 & 845.6922 \\
\hline Power losses (MW) & 58.58 & 56.822 & 50.6162 \\
\hline Total Capacity (MW) & 958.57 & 956.822 & 950.662 \\
\hline
\end{tabular}


Table V Best emission effects for 6-generator system $\left(\mathrm{P}_{\mathrm{D}}=500 \mathrm{MW}\right)$

\begin{tabular}{|l|c|c|c|}
\hline Unit Output & FCGA & NSGA-II & SA \\
\hline P1 (MW) & 81.08 & 56.931 & 58.064 \\
\hline P2 (MW) & 13.93 & 41.542 & 43.721 \\
\hline P3 (MW) & 66.37 & 73.896 & 75.725 \\
\hline P4 (MW) & 85.58 & 84.931 & 83.975 \\
\hline P5 (MW) & 141.70 & 136.502 & 133.454 \\
\hline P6 (MW) & 135.93 & 131.328 & 128.777 \\
\hline Fuel cost (\$/h) & 28756.71 & 28641.078 & 28626.520 \\
\hline Emission (kg/h) & 286.59 & 275.544 & 274.254 \\
\hline Power losses (MW) & 24.61 & 25.129 & 23.717 \\
\hline Total Capacity (MW) & 524.61 & 525.129 & 523.717 \\
\hline
\end{tabular}

Table VI Best emission effects for 6-generator system $\left(\mathrm{P}_{\mathrm{D}}=700 \mathrm{MW}\right)$

\begin{tabular}{|l|c|c|c|}
\hline Unit Output & FCGA & NSGA-II & SA \\
\hline P1 (MW) & 120.16 & 103.078 & 105.329 \\
\hline P2 (MW) & 21.36 & 73.505 & 76.408 \\
\hline P3 (MW) & 62.09 & 91.556 & 92.920 \\
\hline P4 (MW) & 128.05 & 110.787 & 109.834 \\
\hline P5 (MW) & 209.65 & 187.869 & 183.192 \\
\hline P6 (MW) & 201.12 & 174.289 & 170.013 \\
\hline Fuel cost (\$/h) & 39455.00 & 39473.433 & 39433.477 \\
\hline Emission (kg/h) & 516.55 & 467.388 & 462.716 \\
\hline Power losses (MW) & 42.44 & 41.083 & 37.699 \\
\hline Total Capacity (MW) & 742.44 & 741.083 & 737.699 \\
\hline
\end{tabular}

Table VII Best emission effects for 6-generator system $\left(P_{D}=900 \mathrm{MW}\right)$

\begin{tabular}{|l|c|c|c|}
\hline Unit Output & FCGA & NSGA-II & SA \\
\hline P1 (MW) & 133.31 & 124.998 & 124.989 \\
\hline P2 (MW) & 110.00 & 109.893 & 88.322 \\
\hline P3 (MW) & 100.38 & 111.081 & 123.954 \\
\hline P4 (MW) & 119.27 & 141.961 & 134.833 \\
\hline P5 (MW) & 250.79 & 254.36 & 274.647 \\
\hline P6 (MW) & 251.25 & 226.578 & 215.480 \\
\hline Fuel cost (\$/h) & 53299.64 & 51254.195 & 50517.633 \\
\hline Emission $(\mathrm{kg} / \mathrm{h})$ & 785.64 & 760.052 & 751.274 \\
\hline Power losses $(\mathrm{MW})$ & 65.00 & 68.87 & 62.226 \\
\hline Total Capacity (MW) & 965.00 & 968.87 & 962.226 \\
\hline
\end{tabular}

Table VIII Best compromise solution for 6-generator system $\left(\mathrm{P}_{\mathrm{D}}=500 \mathrm{MW}\right)$

\begin{tabular}{|l|c|c|c|}
\hline Unit Output & FCGA & NSGA-II & SA \\
\hline P1 (MW) & 65.23 & 54.048 & 54.720 \\
\hline P2 (MW) & 24.29 & 34.250 & 32.597 \\
\hline P3 (MW) & 40.44 & 54.497 & 49.227 \\
\hline P4 (MW) & 74.22 & 80.413 & 77.730 \\
\hline P5 (MW) & 187.75 & 161.874 & 166.342 \\
\hline P6 (MW) & 125.48 & 135.426 & 137.214 \\
\hline Fuel cost (\$/h) & 28231.06 & 28291.119 & 28164.743 \\
\hline Emission (kg/h) & 304.90 & 284.362 & 282.402 \\
\hline Power losses (MW) & 17.41 & 20.508 & 17.142 \\
\hline Total Capacity (MW) & 517.41 & 520.508 & 517.142 \\
\hline
\end{tabular}

Table IX Best compromise solution for 6-generator system $\left(\mathrm{P}_{\mathrm{D}}=700 \mathrm{MW}\right)$

\begin{tabular}{|l|c|c|c|}
\hline Unit Output & FCGA & NSGA-II & SA \\
\hline P1 (MW) & 80.16 & 86.286 & 84.150 \\
\hline P2 (MW) & 53.71 & 60.288 & 55.655 \\
\hline P3 (MW) & 40.93 & 73.064 & 66.005 \\
\hline P4 (MW) & 116.23 & 109.036 & 107.266 \\
\hline P5 (MW) & 251.20 & 223.448 & 230.931 \\
\hline P6 (MW) & 190.62 & 184.111 & 187.647 \\
\hline Fuel cost (\$/h) & 38408.82 & 38671.813 & 38371.892 \\
\hline Emission (kg/h) & 527.46 & 484.931 & 476.537 \\
\hline Power losses (MW) & 32.85 & 36.234 & 31.656 \\
\hline Total Capacity (MW) & 732.85 & 736.234 & 731.656 \\
\hline
\end{tabular}


Table X Best compromise solution for 6-generator system $\left(\mathrm{P}_{\mathrm{D}}=900 \mathrm{MW}\right)$

\begin{tabular}{|l|c|c|c|}
\hline \multicolumn{1}{|c|}{ Unit Output } & FCGA & NSGA-II & SA \\
\hline P1 (MW) & 111.40 & 120.052 & 115.276 \\
\hline P2 (MW) & 69.33 & 85.203 & 78.809 \\
\hline P3 (MW) & 59.43 & 89.565 & 81.388 \\
\hline P4 (MW) & 143.26 & 140.278 & 137.345 \\
\hline P5 (MW) & 319.40 & 288.614 & 298.677 \\
\hline P6 (MW) & 252.11 & 233.687 & 238.178 \\
\hline Fuel cost (\$/h) & 49674.28 & 50126.059 & 49553.835 \\
\hline Emission (kg/h) & 850.29 & 784.696 & 772.456 \\
\hline Power losses (MW) & 54.92 & 57.405 & 49.676 \\
\hline Total Capacity (MW) & 954.92 & 957.405 & 949.676 \\
\hline
\end{tabular}

Summary of the results in Table II to Table X for the best completion of SA method compared with NSGA-II in order to reduce fuel costs, emissions, and power losses are shown in Table XI. After comparing the simulation results with the others method, it is obviously seen that proposed SA algorithm give more powerful results than other algorithms.

Table XI Summary of SA VS NSGA-II for 6-generator system

\begin{tabular}{|l|r|r|r|}
\hline & \multicolumn{3}{|c|}{ LOAD (MW) } \\
\hline & 500 & \multicolumn{1}{c|}{700} & \multicolumn{1}{|c|}{900} \\
\hline Best fuel cost & & & 322.890 \\
\hline Fuel cost $(\$ / \mathrm{h})$ & 63.888 & 163.155 & 3.633 \\
\hline Emission $(\mathrm{kg} / \mathrm{h})$ & 2.707 & 2.227 & 6.205 \\
\hline Power losses $(\mathrm{MW})$ & 1.089 & 2.964 & 736.561 \\
\hline Best emission & & & 8.777 \\
\hline Fuel cost $(\$ / \mathrm{h})$ & 14.557 & 39.955 & 6.644 \\
\hline Emission $(\mathrm{kg} / \mathrm{h})$ & 1.289 & 4.671 & \\
\hline Power losses $(\mathrm{MW})$ & 1.411 & 3.384 & 572.223 \\
\hline Best compromise & & & 12.239 \\
\hline Fuel cost $(\$ / \mathrm{h})$ & 126.376 & 299.920 & 7.728 \\
\hline Emission $(\mathrm{kg} / \mathrm{h})$ & 1.959 & 8.393 & \\
\hline Power losses $(\mathrm{MW})$ & 3.365 & 4.577 & \\
\hline
\end{tabular}

\section{Conclusion}

In this paper, a SA algorithm has been proposed and successfully applied to solve the CEED problem. Simulation results show that the SA approach provides effective and robust high-quality solution. Moreover, the results obtained using SA are either better or comparable to those obtained using other techniques reported in the literature.

\section{References}

[1] A.J Wood, and B.F. Wollenberg, Power Generation Operation and Control (New York: John Wiley and Sons, 1984).

[2] Hadi Saadat, Power System Analysis (New Delhi: Tata McGraw Hill Publishing Company, 2002).

[3] S.Y. Lim, M. Montakhab, and H. Nouri, Economic dispatch of power system using particle swarm optimization with constriction factor, International Journal of Innovations in Energy Systems and Power, 4(2), 2009, 29-34.

[4] Z. L. Gaing, Particle swarm optimization to solving the economic dispatch considering the generator constraints, IEEE Transactions on Power Systems, 18(3), 2003, 1187-1195.

[5] D. C. Walters, and G. B. Sheble, Genetic algorithm solution of economic dispatch with valve point loading, IEEE Transactions on Power Systems, 8(3), 1993, 1325-1332.

[6] T. Ratniyomchai, A. Oonsivilai, P. Pao-La-Or, and T. Kulworawanichpong, Particle swarm optimization for solving combined economic and emission dispatch problems, 5th IASME/WSEAS Int. Conf. Energy Environ., 2010, 211-216.

[7] N. Cetinkaya, Optimization algorithm for combined economic and emission dispatch with security constraints, Int. Conf. Comp. Sci. Appl. ICCSA, 2009, 150-153.

[8] U. Güvenç, Combined economic emission dispatch solution using genetic algorithm based on similarity crossover, Sci. Res. Essay, 5(17), 2010, 2451-2456.

[9] S. Hemamalini, and S. P. Simon, Economic/emission load dispatch using artificial bee colony algorithm, Int. Conf. Cont., Comm. Power Eng., 2010, 338-343.

[10] Y. Sonmez, Multi-objective environmental/economic dispatch solution with penalty factor using artificial bee colony algorithm, Sci. Res. Essay, 6(13), 2011, 2824-2831.

[11] C. Palanichamy, and N. S. Babu, Analytical solution for combined economic and emissions dispatch, Electr. Power Systs. Res., 78, 2008, 1129-1137.

[12] R. Balamurugan, and S. Subramanian, A simplified recursive approach to combined economic emission dispatch, Electr. Power Comp. Syst., 36(1), 2008, 17-27.

[13] Y. M. Chen, and W. S. Wang, A particle swarm approach to solve environmental/economic dispatch problem, International Journal of Industrial Engineering Computations, 1, 2010, 157-172.

[14] Anurag Gupta, K. K. Swarnkar, and K. Wadhwani, Combined economic emission dispatch problem using particle swarm optimization, International Journal of Computer Applications, 49(6), 2012, 1-6.

[15] P. K. Roy, S. P. Ghoshal, and S. S. Thakur, Combined economic and emission dispatch problems using biogeography-based optimization, Electrical Engineering, 92(4), 2010, 173-184. 
[16] N. Metropolis, A.W. Rosenbluth, M. N. Rosenbluth, A. H. Teller, and E. Teller, Equations of State Calculations by Fast Computing Machines, J. Chem. Phys., 21, 1953, 1087-1092.

[17] S. Kirkpatrick, C. D. Gelatt Jr, and M. P. Vecchi, Optimization by Simulated Annealing, Science, 220, 1983, 671-680.

[18] E. Aarts, and J. Korst, Simulated Annealing and Boltzmann Machines: A Stochastic Approach to Combinatorial Optimization and Neural Computing, (New York: Wiley, 1989).

[19] HCS Rughooputh, and RTFA King, Environmental/economic dispatch of thermal units using an elitist multi-objective evolutionary algorithm, IEEE Int. Conf. Ind. Tech., 2003, 48-53. 